\title{
Antiulcer Activity after Oral Administration of the Wormwood Ethanol Extract on Lesions due to Leishmania major Parasites in BALB/C Mice
}

\section{Kourosh Azizi', Fatemeh Shahidi-Hakak², Mohammad Djaefar Moemenbellah-Fard1*, Qasem Asgari ${ }^{3}$ and Soliman Mohammadi-Samani ${ }^{4}$}

\author{
'Research Centre for Health Sciences, Department of Medical Entomology and Vector Control, \\ School of Health, Shiraz University of Medical Sciences, Shiraz, P. O. Box 71645-111, Iran; \\ azizik@sums.ac.ir,azizi_ko@yahoo.com,momenbf@sums.ac.ir,momenbf@yahoo.com \\ 2Department of Medical Entomology and Vector Control, School of Health, \\ Shiraz University of Medical Sciences, Shiraz, Iran; shahidi_fateme78@yahoo.com \\ ${ }^{3}$ Basic Sciences in Infectious Diseases Research Center, Department of Parasitology and Mycology, \\ School of Medicine, Shiraz University of Medical Sciences, Shiraz, P. O. Box 71348-14336, \\ Iran; qasemasgari@yahoo.com, asgarig@sums.ac.ir \\ ${ }^{4}$ Pharmaceutical Sciences Research Center, School of Pharmacy, Shiraz University of Medical Sciences, \\ Shiraz,Iran; smsamani@sums.ac.ir
}

\begin{abstract}
Herbal extracts were used to investigate the in vivo efficacy of Artemisia absinthium on the treatment of cutaneous leishmaniasis in susceptible mice. A total of $40 \mathrm{BALB} / \mathrm{c}$ mice were subjected to assays. In each, $3-5 \times 10^{3}$ amastigotes of standard Leishmania major strain were inoculated subcutaneously into the tail base of mice. Groups of mice were assigned as: I-negative control, II-positive control, III-Glucantime ${ }^{\circledR}$, IV-ointment twice a day, V-ointment with oral medicine, VI-oral medicine on parasite injection, VII-oral medicine once ulcer develops, and VIII-ointment-based crème on ulcer. The gold standard of clinical infection control was based on ulcer size measurement using a Vernier scale weekly during 4 weeks Post-Ulcer Development (PUD). The mean ulcer sizes in different groups were compared using the post hoc Dunnett's 3 statistical analyses. There was a significant difference between the two groups of ointment with medicine $(\mathrm{V})$ and medicine on parasite inoculation (VI) ( $\mathrm{P} \leq$ 0.027). Antiulcer activity and healing was noted after oral treatment with aqueous extract on parasite injection. There was a significant difference between data from positive control group and local ointment with oral medicine $(\mathrm{P} \leq 0.045)$ indicating that ointment use facilitated ulcer growth. There was also a significant difference between data from Glucantime ${ }^{\circledR}$ use and ointment with medicine group $(P \leq 0.039)$ which showed the deteriorating effect of oil-based ointment use. The oral administration of extract had an effect similar to Glucantime ${ }^{\circledR}$ use and led to the repair of ulcer. A. absinthium extract as oral feeder appeared to cause modulation of host responses, ulcer size reduction and tissue repair.
\end{abstract}

Keywords: Artemisia, Balb/c mice, Glucantime®, Leishmania major, Treatment

${ }^{*}$ Author for correspondence 


\section{Introduction}

Cutaneous Leishmaniases (CL), as ulcerative skin lesions caused by the flagellate protozoan parasites in the genus Leishmania (Kinetoplastida: Trypanosomatidae), represent widespread neglected zoonotic and public health diseases being endemic in most developing countries of Africa, Latin America, and Asia including $\operatorname{Iran}^{42}$. CL is the second most important vector-borne protozoan disease in Iran, after malaria ${ }^{28}$. The national incidence rate of CL disease has risen from 0.002 to 1.337 over the first decade of this century ${ }^{22}$. CL transmission is, however, anthroponotic or zoonotic based on whether the main reservoir host is human or other mammals ${ }^{34}$. Among 15 well-defined Leishmania species known to cause parasitic infection in humans, 13 have a zoonotic natural history ${ }^{16}$. Most transmission cycles of Iranian CL cases are zoonoses ${ }^{27}$. The parasite is transmitted by the female blood-sucking phlebotomine sand flies (Diptera: Psychodidae) often feeding on rodent reservoir hosts prior to biting humans ${ }^{2,3}$.

Chemotherapy with pentavalent antimonial drugs, like meglumine antimoniate (Glucantime ${ }^{\circ}$ ), is still the mainstay activity in endemic areas of $\operatorname{Iran}^{17}$. CL treatment is often impeded by the development of drug resistance ${ }^{11}$, side effects like cardiac and renal toxicities, variable efficacy, necessity to endure long courses of parenteral administration, the absence of an effective vaccine, as well as the formidable task of developing a simple, cheap, sustainable and swift drug-evaluating system globally effective on the different Leishmania species/strains infecting humans; though this being too optimistic ${ }^{20}$. Attempts to identify alternative search strategies are thus conspicuously essential ${ }^{25}$. About $80 \%$ of the world's inhabitants depend on folk medicines for their healthcare9 Traditional treatment of CL includes the administration of natural products from medicinal herbs such as wormwood, Artemisia, in some parts of the world ${ }^{6,35}$.

Medicinal herbs are normally rich sources of various types of bioactive organic compounds. The medicinal plant genus Artemisia is one of the largest and most widespread members of the daisy family in the world which includes about 500 species growing mostly in temperate regions of Asia, Europe and North America ${ }^{5}$. One of these botanicals, known commonly as the absinthe wormwood Artemisia absinthium L. (Asteraceae/Compositae), is an aromatic perennial herb with silvery-green foliage growing naturally native on dry open slopes in Fars province, south Iran. They are characterized to have multiple diverse effects. Their efficacy could be due to the composition and biochemical effects of various volatile Essential Oils (EOs) which are reported to have antifungal $^{40}$, antimicrobial ${ }^{12,31}$, and antiparasitic ${ }^{1,39}$ effects against Leishmania species. Additionally, certain EOs from A. absinthium has been reported to bear acaricidal ${ }^{8}$, insecticida $^{23}$, and repellent activities against fleas, flies, gnats, and ticks ${ }^{21}$.

Much of the studies on the detection of natural medicinal products with anti-Leishmania activity have been performed using the promastigote (flagellate) or sand fly stage of the parasite as it is more amenable to maintain under in vitro conditions. However, since the extracellular promastigote is not the pathogenic form of the parasite in vertebrate hosts, assays carried out with promastigotes have solely an indicative value of the likely anti-Leishmania activity of the herbal extract or its metabolite tested. An initial evaluation using promastigotes have thus to be complemented with an assay on intracellular amastigotes within parasitophorous vacuoles of vertebrate host's macrophages ${ }^{7}$. Consequently, a recent study was conducted on the in vitro activities of A. absinthium on Leishmania major parasites, using a series of synchronous cell sensitivity and flow cytometry assays ${ }^{4}$. A growth inhibitory concentration $\left(\mathrm{IC}_{50}\right)$ and a lethal concentration $\left(\mathrm{LC}_{50}\right.$ ) of 16.6 and $101 \mu \mathrm{gml}^{-1}$ were thus recorded, respectively. In the present study, the main aim was to unravel the in vivo antiulcer efficacy of $A$. absinthium medicinal herb ethanol extract on the treatment of CL lesions caused by L. major parasites in susceptible BALB/c mice. To the best of authors' knowledge, there appear to have been no previous reports on the in vivo effects of absinthe wormwood against lesions induced by $L$. major amastigotes parasites within the scope of this investigation.

\section{Materials and Methods}

Plant identification, preparation, and isolation of its extracts as well as parasite culture were previously described $^{4}$. The hydro alcoholic extract obtained from A. absinthium was then delivered to pharmaceutical Department of the School of Pharmacy for the preparation of $90 \%$ ointment. The creme based formulation comprised $18 \mathrm{~g}$ liquid paraffin, $7 \mathrm{~g}$ Vaseline, $5 \mathrm{~g}$ Cetostearyl alcohol, $3 \mathrm{~g}$ Cetomacrogol, $0.5 \mathrm{~g}$ Carbomer in $70 \mathrm{~g}$ distilled water, and $5 \mathrm{ml}$ of one normal sodium hydroxide $(\mathrm{NaOH})$. 


\subsection{Laboratory Animals}

All experimental animals were susceptible BALB/c male mice between 4-6 weeks old and weighing 18-24 g which were supplied from the Institute of Pasteur at the Iranian capital city of Tehran. These mice were grouped into eight batches of five mice as follows:

- Group I: Naïve uninfected mice but oral treatment with drug (negative control).

- Group II: Untreated but infected with amastigote parasites (positive control).

- Group III: Intramuscular Glucantime ${ }^{\bullet}$ injection 3 weeks Post-Ulcer Development (PUD).

- Group IV: Local ointment twice (A.M. and P.M.) a day PUD.

- Group V: Local ointment twice daily with oral medicine PUD.

- Group VI: Aqueous oral medicine upon parasite inoculation.

- Group VII: Aqueous oral medicine once ulcer appears.

- Group VIII: Local application of ointment-based crème once ulcer appears.

\subsection{Parasite Inoculation into Susceptible $\mathrm{BALB} / \mathrm{c}$ Mice}

Experimental infections of susceptible $\mathrm{BALB} / \mathrm{c}$ mice were performed using Leishmania major parasitic amastigotes. To inoculate parasites, the lesion clots from $5 \mathrm{~L}$. major-infected mice were removed after detachment. The serosal fluids from below lesion clots were taken up and transferred to physiological sera. A suspension of parasites, physiological serum and antibiotics $(100 \mu \mathrm{g} /$ $\mathrm{ml}$ streptomycin, and penicillin $100 \mathrm{U} / \mathrm{ml}$ ) were thus prepared. Using a Neobar Chamber slide on an inverted compound microscope, parasite counts were examined by taking samples from this suspension. In addition, a drop of amastigote parasites suspension was poured onto a microscope slide, air-dried, methanol-fixed, and stained in Giemsa for direct observation. All susceptible BALB/c mice, except those in the first group, were subcutaneously inoculated at their tail base with equal volumes of $3-5 \times 10^{3}$ amastigotes of standard Iranian $L$. major parasite strain $\mathrm{MRHO} / \mathrm{IR} / 75 / \mathrm{ER}$. After three weeks of parasite inoculation, a raised nodule was felt at the site of entry which resulted in an open ulcer.

\subsection{Treatments and Measurements}

The first naïve group was solely treated with oral medicine. Those groups which were treated with oral medicine received $1.4 \mathrm{~g} / \mathrm{kg}$ drug daily. The second group (positive control) did not receive any treatment as it was solely inoculated with parasites. The groups of I, II, IV, V, and VIII were followed up and except group II received treatments for 4 weeks. The groups of VI and VII were treated for 5 weeks. The mice in group III received daily intramuscular (i.m.) inoculation of $0.6 \mathrm{mg} / \mathrm{kg}$ Glucantime ${ }^{\star}$ for a period of 21 days (Figure 1).

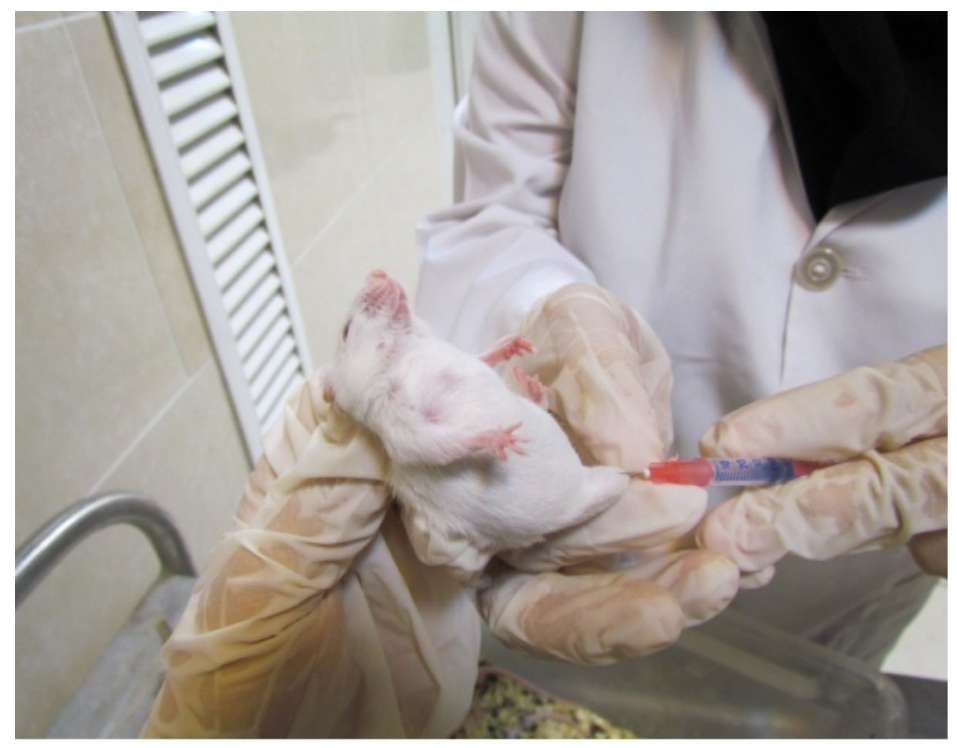

Figure 1. A BALB/c mouse is being injected with Glucantime ${ }^{\circledR}$ drug into its calf muscle. 
Prior to treatments, the ulcer areas on mice in each experimental group were recorded following measurements. They were also re-measured during the course of treatments once a week and the data on ulcer areas were noted. The length and width of each ulcer were directly measured with a Collis Vernier caliper scale, and its area was calculated using the formula of: $S=a / 2 . b / 2 . \pi$; where 'a' variable was the length and ' $b$ ' was the width of each ulcer.

\subsection{Data Analysis}

In order to compare the mean size of ulcers between different mice groups, the statistical test of Analysis of Variance (ANOVA) was used. Data analysis by ANOVA was significant, but the presumption of equal variances was not established. Therefore, the post hoc Dunnett's T3 statistical analyses were used to determine the efficacy of different treatment regimes. In addition, $P$-values of 0.05 or less (or a confidence interval of 95\%) were considered significant. Data analysis was done using SPSS software version 16.

\section{Results}

The data analysis revealed that there was a significant difference between ulcer sizes in the two groups of $\mathrm{V}$ and VI ( $\mathrm{P} \leq 0.027)$; that is oral medicine upon parasite inoculation and ointment twice daily with oral medicine post-ulcer development; PUD (Table 1). This ameliorative response of lesion growth retardation was similar to that of the oral administration of Glucantime ${ }^{\odot}$ PUD which culminated in lesion repair and resolution. The outcome of positive control (untreated infected) group with those of fifth (ointment with oral medicine) group were also significantly different $(\mathrm{P} \leq 0.045)$; such that local ointment application accompanied by oral medicine administration led to the exacerbation of lesion growth (Table 2). The Glucantime-treated and the ointment with oral medicine groups also showed a significant difference $(P \leq 0.039)$ reflecting that the oil-based ointment caused an aggravating effect on lesion size. In contrast, oral administration of herbal medicine upon parasite inoculation and once ulcer develops did not exhibit any significant statistical difference with the Glucantime group $(P \geq 0.05)$. These oral protocols led to a repair and reduction of lesion size.

In the present study, an ulcer developed on average about 35 day post-inoculation of amastigote parasites into the mice. As indicated in Table 1, the biggest ulcer size had a mean area of about $141.86 \mathrm{~mm}^{2}$ due to the local application of ointment twice daily with oral medicine PUD, so that there was a 5 -fold increase in the mean ulcer size from the start to the end of this treatment. The largest ulcer growth rate was noted in group IV using local ointment twice (A.M. and P.M.) a day PUD without any oral administration, such that there was an 8.87-fold increase in the mean ulcer size from the start to the end of treatment. On the other hand, the smallest ulcer size with a final mean area of about $14.64 \mathrm{~mm}^{2}$ was recorded in that group of mice receiving aqueous oral medicine upon parasite inoculation. The mean ulcer size from the start to the end of this treatment grew by only 1.03 -fold. Likewise, the mean ulcer size in Glucantime ${ }^{\oplus}$ group grew by 1.6 -fold which indicated that oral drug administrations have had meaningful effects on the prevention of lesion growth due to the intracellular proliferation of $L$. major amastigote parasites within tissue macrophages.

Table 1. Average lesion size $\left(\mathrm{mm}^{2}\right)$ and its growth rate among different treatment groups of mice during a five-week period

\begin{tabular}{lcccccc}
\hline Groups $^{\dagger} /$ Weeks & $\mathbf{1}$ & $\mathbf{2}$ & $\mathbf{3}$ & $\mathbf{4}$ & $\mathbf{5}$ & Lesion growth rate \\
\hline I: -ve. Control & - & - & - & - & - & - \\
II: +ve. Control & 6.76 & 16.76 & 20.78 & 22.84 & - & 3.37 \\
III: Glucantime PUD* & 11.07 & 18.38 & 17.82 & - & - & 1.60 \\
IV: Oint. PUD & 10.17 & 44.44 & 59.19 & 90.23 & - & 8.87 \\
V: Oint./Oral PUD & 28.16 & 68.84 & 81.74 & 141.86 & - & 5.03 \\
VI: Oral on Inject. & 10.14 & 8.75 & 8.24 & 10.92 & 14.64 & 1.44 \\
VII: Oral on Ulcer & 12.80 & 16.99 & 22.93 & 29.68 & 29.23 & 2.28 \\
VIII: Oint.-base crème & 12.90 & 19.59 & 42.02 & 47.67 & - & 3.69 \\
\hline
\end{tabular}

$\dagger$ Numbers I-VIII refer to different treatment protocols, $*$ PUD $=$ post ulcer development. 
Table 2. Statistical analyses from multiple comparisons of oral and local wormwood extract administrations under in vivo conditions on $\mathrm{BALB} / \mathrm{c}$ mice using pair wise Dunnett's T3 test to determine the significant differences between different variables.

\begin{tabular}{|c|c|c|c|c|c|c|}
\hline \multirow[t]{2}{*}{ Variable $^{\dagger}(\mathrm{I})$} & \multirow[t]{2}{*}{ Variable $^{\dagger}(\mathrm{J})$} & \multirow{2}{*}{$\begin{array}{c}\text { Mean difference } \\
(\mathrm{I}-\mathrm{J})\end{array}$} & \multirow[t]{2}{*}{ Standard error } & \multirow[t]{2}{*}{ Significance level } & \multicolumn{2}{|c|}{ 95\% Confidence interval } \\
\hline & & & & & Lower limit & Upper limit \\
\hline \multirow[t]{6}{*}{ II } & III & 1.02400 & 8.68868 & 1.000 & -36.1334 & 38.1814 \\
\hline & IV & -34.22000 & 20.07622 & 0.788 & -137.1351 & 68.6951 \\
\hline & $\mathrm{V}$ & $-63.37600^{*}$ & 12.94557 & 0.045 & -125.0324 & -1.7196 \\
\hline & VI & 6.24800 & 7.80993 & 1.000 & -26.2494 & 38.7454 \\
\hline & VII & -5.54400 & 12.90244 & 1.000 & -66.9482 & 55.8602 \\
\hline & VIII & -13.76000 & 14.01266 & 0.993 & -81.6496 & 54.1296 \\
\hline \multirow[t]{6}{*}{ III } & II & -1.02400 & 8.68868 & 1.000 & -38.1814 & 36.1334 \\
\hline & IV & -35.24400 & 20.82109 & 0.797 & -135.5404 & 64.9624 \\
\hline & $\mathrm{V}$ & $-64.40000^{*}$ & 14.07307 & 0.039 & -125.5228 & -3.2772 \\
\hline & VI & 5.22400 & 9.56338 & 1.000 & -34.0709 & 44.5189 \\
\hline & VII & -6.56800 & 14.03339 & 1.000 & -67.4690 & 54.3330 \\
\hline & VIII & -14.78400 & 15.06047 & 0.994 & -81.4910 & 51.9230 \\
\hline \multirow[t]{6}{*}{ IV } & II & 34.22000 & 20.07622 & 0.788 & -68.6951 & 137.1351 \\
\hline & III & 35.24400 & 20.82109 & 0.797 & -64.9624 & 135.4504 \\
\hline & $\mathrm{V}$ & -29.15600 & 22.92624 & 0.959 & -128.2830 & 69.9710 \\
\hline & VI & 40.46800 & 20.46997 & 0.659 & -60.8072 & 141.7432 \\
\hline & VII & 28.67600 & 22.90191 & 0.963 & -70.4252 & 127.7772 \\
\hline & VIII & 20.46000 & 23.54526 & 0.999 & -79.5388 & 120.4588 \\
\hline \multirow[t]{6}{*}{$\mathrm{V}$} & II & $63.37600^{*}$ & 12.94557 & 0.045 & 1.7196 & 125.0324 \\
\hline & III & $64.40000^{*}$ & 14.07307 & 0.039 & 3.2772 & 125.5228 \\
\hline & IV & 29.15600 & 22.92624 & 0.959 & -69.9710 & 128.2830 \\
\hline & VI & $69.62400^{*}$ & 13.54817 & 0.027 & 8.6822 & 130.5658 \\
\hline & VII & 57.83200 & 17.00091 & 0.121 & -11.5144 & 127.1784 \\
\hline & VIII & 49.61600 & 17.85812 & 0.271 & -23.3993 & 122.6313 \\
\hline \multirow[t]{6}{*}{ VI } & II & -6.24800 & 7.80993 & 1.000 & -38.7454 & 26.2494 \\
\hline & III & -5.22400 & 9.56338 & 1.000 & -44.5189 & 34.0709 \\
\hline & IV & -40.46800 & 20.46997 & 0.659 & -141.7432 & 60.8072 \\
\hline & $\mathrm{V}$ & $-69.62400^{*}$ & 13.54817 & 0.027 & -130.5658 & -8.6822 \\
\hline & VII & -11.79200 & 13.50696 & 0.998 & -72.4962 & 48.9122 \\
\hline & VIII & -20.00800 & 14.57119 & 0.927 & -86.8773 & 46.8613 \\
\hline \multirow[t]{6}{*}{ VII } & II & 5.54400 & 12.90244 & 1.000 & -55.8602 & 66.9482 \\
\hline & III & 6.56800 & 14.03339 & 1.000 & -54.3330 & 67.4690 \\
\hline & IV & -28.67600 & 22.90191 & 0.963 & -127.7772 & 70.4252 \\
\hline & $\mathrm{V}$ & -57.83200 & 17.00091 & 0.121 & -127.1784 & 11.5144 \\
\hline & VI & 11.79200 & 13.50696 & 0.998 & -48.9122 & 72.4962 \\
\hline & VIII & -8.21600 & 17.82687 & 1.000 & -81.1185 & 64.6865 \\
\hline \multirow[t]{6}{*}{ VIII } & II & 13.76000 & 14.01266 & 0.993 & -54.1296 & 81.6496 \\
\hline & III & 14.78400 & 15.06047 & 0.994 & -51.9230 & 81.4910 \\
\hline & IV & -20.46000 & 23.54526 & 0.999 & -120.4588 & 79.5388 \\
\hline & $\mathrm{V}$ & -49.61600 & 17.85812 & 0.271 & -122.6313 & 23.3993 \\
\hline & VI & 20.00800 & 14.57119 & 0.927 & -46.8613 & 86.8773 \\
\hline & VII & 8.21600 & 17.82687 & 1.000 & -64.6865 & 81.1185 \\
\hline
\end{tabular}

$\dagger$ Numbers II-VIII refer to different treatment protocols, *The mean difference is significant at the 0.05 level. 


\section{Discussion}

Cutaneous leishmaniasis mostly caused by the intracellular Leishmania major amastigote parasites remains a formidable therapeutic challenge and a serious public health concern in most tropical countries, including Iran $^{2,3}$, though occasionally other infectious and noninfectious diseases could also be superimposed ${ }^{13,18,29}$. Although the pentavalent antimony compounds such as sodium stibogluconate (Pentostam; ${ }^{\circ}$ Glaxco Wellcome, UK) and meglumine antimoniate (Glucantime ${ }^{\circledR}$; Aventis, France) are the first-line drugs used in the treatment of all forms of leishmaniases, the report of cases of resistance to these drugs and the fact that they have to be administered parenterally represent the main hurdles for the chemotherapy of leishmaniases ${ }^{11}$. Unfortunately, no ideal treatments for the leishmaniases have yet been advocated ${ }^{9}$.

There appears to be a new herbalism trend in search of folk medicines to treat human infectious diseases with increasing frequency ${ }^{41}$. Novel approaches including the oral administration of natural pharmaceutical products from medicinal herbs such as wormwood, Artemisia, have been proposed ${ }^{33}$. The currently well-known anti-malaria compound, artemisinin (a sesquiterpene with an endoperoxide bridge), is derived from this plant ${ }^{24,36}$. In the in vivo test, this compound in micromolar concentrations has been reported to reduce the severity of lesions caused by Leishmania amazonensis in BALB/c mice ${ }^{14}$. The toxicity of artemisinin derivatives for laboratory animals and its safe use in man have also been reviewed ${ }^{15}$. The rapid reduction of parasitaemia and short elimination half-life (with an almost immediate effect) of these compounds after oral administration are elucidated in this review. The toxicity resulting from the oil-based formulations is also implicated, which is compatible with the data from the present study. Orally administered chemotherapeutic agents (e.g., as salt) have the privilege of minimizing socioeconomic problems associated with populations living in endemic areas where the infrastructure of health care facilities is rudimentary ${ }^{30}$.

The leaf and seed extracts of the annual or sweet wormwood, Artemisia annua, have been shown to mediate apoptosis in Leishmania donovani, the cause of visceral leishmaniasis (Kala-azar) in the Indian subcontinent ${ }^{19}$. Furthermore, the in vivo studies have indicated that a $70 \%$ ethanol extract from the commonly used vegetable, known in Iran as Tarkhoon (Aretmisia dracunculus), had potent anti-inflammatory (or antiulcer) activity ${ }^{32}$. Other studies have confirmed that the leaves from this medicinal herb have inhibitory effects on blood platelet adhesion and aggregation in rats ${ }^{37}$. This could mean swift flow of blood from the site of lesion and carriage of Leishmaniainfected macrophages to remote vessels where they can readily be cleared by the host's immune responses.

The main aim of using an animal model such as mice is to deplore a drug that can be administered orally, be effective in a short period ( $<10$ days) and have minimal sign of side-effects at the highest testable doses $(100 \mathrm{mg} /$ $\mathrm{kg}$ ). According to recent reports ${ }^{10,26}$, the BALB/c mouse - L. major model has extensively been used in drug discovery studies but it is an exceptionally rigorous non-cure model in which the most active drugs have any efficacy and absolute cure is scarce. The treatment of CL is difficult due to the intracellular (within macrophages) location and replication of the infectious Leishmania amastigote parasites. The main observation from the present study was that oral in vivo treatment with an aqueous extract of A. absinthium was found to be effective in experimental murine models of CL. As oral administration of this herbal extract provided a prolonged slow release of active ingredients in mice which probably potentiated the host immune responses, the lesion growth rate was thus minimized with this route of administration compared with other choices. In contrast, the dermal application of an ointment-based crème formulation culminated in increased lesion growth rate indicating that the oil-based moiety prevented lesion resolution. This finding was in accordance with other studies ${ }^{15}$. The present finding, that oral herbal extract administration was also slightly more effective than Glucantime ${ }^{\circledR}$ i.m. use, was supported by the data reported from another similar in vivo model system using Artemisia auchery ${ }^{38}$.

One of the main limitations of this study was that the determination of drug efficacy by scoring 3-dimensional changes in lesion size during and after the course of treatment could be biased as much of the lesion consists of inflammatory cells such as macrophages filled with amastigotes limited to the dermal layer of the skin. Culturing parasites from skin biopsies gives an alternative quantitative score of activity ${ }^{10}$. This was accomplished in a recent publication ${ }^{4}$.

The lack of a suitable association between the data acquired by the in vitro bioassays and those from the in vivo evaluations, as well as the necessity to have rapid and simple evaluation procedures in which all species and 
strains of Leishmania could be incorporated, have stimulated the search for novel bioassay techniques to confirm leishmanicidal activity ${ }^{7}$. This is exemplified by the follow up and uptake by parasites of radioactive trace elements such as the use of tritiated hydrogen $\left[{ }^{3} \mathrm{H}\right]$ atom in medicinal herbs.

It was thus concluded from the present data that oral administration of $A$. absinthium herbal extract due to its pharmaceutical chemical entities had the most therapeutic effect on lesions due to the $L$. major amastigote parasites in susceptible $\mathrm{BALB} / \mathrm{c}$ mice. It seems that $A$. absinthium extract as an oral feeder caused modulation of host responses, ulcer size reduction and tissue repair. In contrast, ointment formulation from this extract had an inverse effect on ulcer size and its diameter increased possibly due to its impregnation with an oil moiety.

\section{Conflict of Interest}

The authors declare that there is no conflict of interests.

\section{Acknowledgements}

The present paper was extracted from the results of an approved MSc student thesis (No: 90-01-42-3213 Dated 17 March 2011) conducted by the second author, Ms. Fatemeh Shahidi-Hakak. It was financially supported by Shiraz University of Medical Sciences (SUMS). Thanks are due to the Vice-chancellor for Research and Technology at SUMS, for permitting the use of facilities at the university.

\section{References}

1. Abdel-Sattar E, Maes L, Salama MM. In vitro activities of plant extracts from Saudi Arabia against malaria, leishmaniasis, sleeping sickness and Chagas disease. Phytother Res. 2010; 24(9):1322-8.

2. Azizi K, Fakoorziba MR, Jalali M, Moemenbellah-Fard MD. First molecular detection of Leishmania major within naturally infected Phlebotomus salehi from a zoonotic cutaneous leishmaniasis focus in southern Iran. Trop Biomed. 2012; 29(1):1-8.

3. Azizi K, Moemenbellah-Fard MD, Kalantari M, Fakoorziba MR. Molecular detection of Leishmania major kDNA from wild rodents in a new focus of zoonotic cutaneous leishmaniasis in an oriental region of Iran. Vector-Borne Zoonotic Dis. 2012; 12(10):844-50.
4. Azizi K, Shahidi-Hakak F, Asgari Q, Hatam GR, Fakoorziba $\mathrm{MR}$, Miri R, et al. In vitro efficacy of ethanolic extract of Artemisia absinthium (Asteraceae) against Leishmania major L using cell sensitivity and flow cytometry assays. J Parasit Dis. 2014. (In Press).

5. Bailen M, Julio LF, Diaz CE, Sanz J, Martinez-Diaz RA, Cabrera R, et al. Chemical composition and biological effects of essential oils from Artemisia absinthium L cultivated under different environmental conditions. Indust Crops Prod. 2013; 49:102-7.

6. Carvalho PB, Ferreira EI. Leishmaniasis phytotherapy. Nature's leadership against an ancient disease. Fitoterapia. 2001; 72(6):599-618.

7. Chan-Bacab MJ, Pena-Rodriguez LM. Plant natural products with leishmanicidal activity. Nat Prod Rep. 2001; 18:674-88.

8. Chiasson H, Belanger A, Bostanian N, Vincent C, Poliquin A. Acaricidal properties of Artemisia absinthium and Tanacetum vulgare (Asteraceae) essential oils obtained by three methods of extraction. J Econ Entomol. 2001; 94(1):167-71.

9. Croft SL, Coombs GH. Leishmaniasis- current chemotherapy and recent advances in the search for novel drugs. Trends Parasitol. 2003; 19(11):502-8.

10. Croft SL, Seifert K, Yardley V. Current scenario of drug development for leishmaniasis. Ind J Med Res. 2006; 123(3):399-410.

11. Croft SL, Sundar S, Fairlamb A. Drug resistance in leishmaniasis. Clin Microbiol Rev. 2006; 19(1):111-26.

12. Erel BS, Reznicek G, Senol SG, Yavasogulu NUK, Konyalioglu S, Zeybek AU. Antimicrobial and antioxidant properties of Artemisia $L$ species from western Anatolia. Turk J Biol. 2012; 36(1):75-84.

13. Fakoorziba MR, Golmaohammadi P, Moradzadeh R, Moemenbellah-Fard MD, Azizi K, Davari B, et al. Reverse transcription PCR-based detection of Crimean-Congo hemorrhagic fever virus isolated from ticks of domestic ruminants in Kurdistan province of Iran. Vector-Borne Zoonotic Dis. 2012; 12(9):794-9.

14. Fournet A, Munoz V, Roblot F, Hocquemiller R, Cave A, Gantier J. Antiprotozoal activity of dehydrozaluzanin C, a sesquiterpene lactone isolated from Munnozia maronii (Asteraceae). Phytother Res. 1993; 7(2):111-5.

15. Gordi T, Lepist EI. Artemisinin derivatives: Toxic for laboratory animals, safe for humans? Toxicol Let. 2004; 147(2):99-107.

16. Gramiccia M, Gradoni L. The current status of zoonotic leishmaniases and approaches to disease control. Int J Parasitol. 2005; 35(11-12):1169-80.

17. Hadighi R, Mohebali $M$, Boucher $P$, Hajjaran $H$, Khamesipour A, Ouellette M. Unresponsiveness to 
glucantime treatment in Iranian cutaneous leishmaniasis due to drug-resistant Leishmania tropica parasites. PLoS Med. 2006; 3(5):e162.

18. Hassanzadeh J, Mohammadbeigi A, Eshrati B, Moemenbellah-Fard MD. Estimation of the regional burden of non-communicable diseases due to obesity and overweight in Markazi province, Iran, 2006-2007. J Cardiovasc Dis Res. 2012; 3(1):26-31.

19. Islamuddin M, Farooque A, Dwarakanath BS, Sahal D, Afrin F. Extracts of Artemisia annua leaves and seeds mediate programmed cell death in Leishmania donovani. J Med Microbiol. 2012; 61:1709-18.

20. Iwu MM, Jackson JE, Schuster BG. Medicinal plants in the fight against leishmaniasis. Parasitol Today. 1994; 10(2):658.

21. Jaenson T, Palsson K, Borg-Karlson AK. Evaluation of extracts and oils of tick-repellent plants from Sweden. Med Vet Entomol. 2005; 19(4):345-52.

22. Karimi A, Hanafi-Bojd AA, Yaghoobi-Ershadi MR, Akhavan AA, Ghezelbash Z. Spatial and temporal distributions of phlebotomine sand flies (Diptera: Psychodidae), vectors of leishmaniasis, in Iran. Acta Trop. 2014; 132:1319.

23. Kordali S, Aslan I, Calmasur O, Cakir A. Toxicity of essential oils isolated from three Artemisia species and some of their major components to granary weevil, Sitophilus granarius L (Coleoptera: Curculionidae). Indust Crops Prod. 2006; 23(2):162-70.

24. Krishna S, Bustamante L, Haynes RK, Staines HM. Artemisinins: Their growing importance in medicine. Trends Pharmacol Sci. 2008; 29(10):520-7.

25. Manzano JI, Garcia-Hernandez R, Castanys S, Gamarro F. A new ABC half-transporter in Leishmania major is involved in resistance to antimony. Antimicrob Agents Chemother. 2013; 57(8):3719-30.

26. Mears ER, Modabber F, Don R, Johnson GE. A review: The current in vivo models for the discovery and utility of new anti-leishmanial drugs targeting cutaneous leishmaniasis. PLoS Negl Trop Dis. 2015; 9(9):e0003889.

27. Moemenbellah-Fard MD, Kalantari M, Rassi Y, Javadian E. The PCR-based detection of Leishmania major infections in Meriones libycus (Rodentia: Muridae) from southern Iran. Ann Trop Med Parasitol. 2003; 97(8):811-6.

28. Moemenbellah-Fard MD, Saleh V, Banafshi O, Dabaghmanesh T. Malaria elimination trend from a hypo-endemic unstable active focus in southern Iran: Predisposing climatic factors. Pathog Glob Health. 2012; 106(6):358-65.
29. Moemenbellah-Fard MD, Shahriari B, Azizi K, Fakoorziba MR, Mohammadi J, Amin M. Faunal distribution of fleas and their blood-feeding preferences using enzyme-linked immunosorbent assays from farm animals and human shelters in a new rural region of southern Iran. J Parasit Dis. 2014. (In Press).

30. Nakayama H, Loiseau PM, Bories C, Torres de Ortiz S, Schinini A, Serna E, et al. Efficacy of orally administered 2-substituted quinolines in experimental murine cutaneous and visceral leishmaniases. Antimicrob Agents Chemother. 2005; 49(12):4950-6.

31. Nasrabadi HG, Abbaszadeh S, Hashtjin NT, Yamrali I. Study of chemical composition of essential oil of afsantine (Artemisia absinthium) and inhibitory effects of the essential oil and its aqueous and alcoholic extracts on some food-borne bacterial pathogens. J Med Plants. 2012; 11(42):120-7.

32. Obolskiy D, Pischel I, Feistel B, Glotov N, Heinrich M. Artemisia dracunculus L. (tarragon): A critical review of its traditional use, chemical composition, pharmacology, and safety. J Agri Food Chemistry. 2011; 59(21):11367-84.

33. Rath K, Taxis K, Walz G, Gleiter CH, Li SM, Heide L. Pharmacokinetic study of artemisinin after oral intake of a traditional preparation of Artemisia annua L (annual wormwood). Am J Trop Med Hyg. 2004; 70(2):128-32.

34. Reithinger R, Dujardin JC, Louzir H, Pirmez C, Alexander B, Brooker S. Cutaneous leishmaniasis. Lancet Infect Dis. 2007; 7:581-96.

35. Rocha LG, Almeida JRGS, Macedo RO, Barbosa-Filho JM. A review of natural products with antileishmanial activity. Phytomed. 2005; 12(6-7):514-35.

36. Sen R, Bandyopadhyay S, Dutta A, Mandal G, Ganguly S, Saha $\mathrm{P}$, et al. Artemisinin triggers induction of cell-cycle arrest and apoptosis in Leishmania donovani promastigotes. J Med Microbiol. 2007; 56:1213-8.

37. Shahriyary L, Yazdanparast R. Inhibition of blood platelet adhesion, aggregation and secretion by Artemisia dracunculus leaves extracts. J Ethnopharmacol. 2007; 114(2):194-8.

38. Sharif M, Daryani A, Rostami M, Nahrevanian $H$, Azadbakht M. Evaluation of anti-leishmanial efficacy by in vivo administration of herbal extract Artemisia auchery on Leishmania major in BALB/c mice. Pharmacologyonline. 2009; 2:477-85.

39. Tariku Y, Hymete A, Hailu A, Rohloff J. In vitro evaluation of antileishmanial activity and toxicity of essential oils of Artemisia absinthium and Echinops kebericho. Chem Biodiver. 2011; 8(4):614-23. 
40. Umpierrez ML, Lagreca ME, Cabrera R, Grille G, Rossini C. Essential oils from Asteraceae as potential biocontrol tools for tomato pests and diseases. Phytochem Rev. 2012; 11(4):1-12.

41. World Health Organization. Traditional and modern medicine: Harmonizing two approaches. Rep Consult Meet
22-26 November 1999, Beijing, China. WHO West Pacific Region; 2000.

42. World Health Organization. Control of the Leishmaniases. WHO Tech Rep Ser 949 Geneva, Switzerland; 2010. 